Short communication

\title{
Assessing in near real time the impact of the April 2010 Eyjafjallajökull ash plume on air quality
}

\author{
Augustin Colette $^{\mathrm{a}, *}$, Olivier Favez ${ }^{\mathrm{a}}$, Frédérik Meleux ${ }^{\mathrm{a}}$, Laura Chiappini ${ }^{\mathrm{a}}$, Martial Haeffelin ${ }^{\mathrm{b}}$, \\ Yohann Morille $^{c}$, Laure Malherbe ${ }^{a}$, Arnaud Papin ${ }^{a}$, Bertrand Bessagnet ${ }^{a}$, \\ Laurent Menut ${ }^{c}$, Eva Leoz $^{\mathrm{a}}$, Laurence Rouïl ${ }^{\mathrm{a}}$ \\ a INERIS, BP2, 60550 Verneuil-en-Halatte, France \\ b Institut Pierre-Simon Laplace, CNRS, Ecole Polytechnique, 91128 Palaiseau Cedex, France \\ ${ }^{c}$ Laboratoire de Météorologie Dynamique, Institut Pierre-Simon Laplace, CNRS, Ecole Polytechnique, 91128 Palaiseau Cedex, France
}

\section{A R T I C L E I N F O}

Article history:

Received 16 June 2010

Received in revised form

27 September 2010

Accepted 29 September 2010

Keywords:

Air quality

Eyjafjallajökull

Long range transport

Lidar remote sensing

Chemistry transport modelling

\begin{abstract}
A B S T R A C T
The eruption of the Eyjafjallajökull in April 2010 led to the injection in the troposphere of an important quantity of volcanic ash whose advection towards densely populated areas raised serious concerns regarding potential impacts on air quality. Here we investigate to what extent air quality in France was altered using exclusively quantitative data that was available in near real-time. We rely on a combination of atmospheric dispersion modelling, ground-based remote sensing, and chemical characterization of airborne particles. One week after the onset of the eruption we were able to conclude that the Eyjafjallajökull ash plume was locally responsible for an increase of up to $30 \pm 10 \mu \mathrm{g} \mathrm{m}^{-3}$ of total PM10 (particulate matter finer than $10 \mu \mathrm{m}$ ) that reached $65 \mu \mathrm{g} \mathrm{m}-3$ on 18 and 19 April 2010. The methodology presented in this letter offers promising perspectives in terms of emergency response strategy when facing such unforeseen atmospheric dispersion events.
\end{abstract}

(c) 2010 Elsevier Ltd. All rights reserved.

\section{Introduction}

In the first days of the eruption, the Eyjafjallajökull plume presented an unusual load of fine volcanic ash, smaller in size than $10 \mu \mathrm{m}$ (Thordarson, 2010). Such particles do not settle gravitationally as fast as very coarse ash, and can thus be transported over long distances. Their long range transport is favoured by anticyclonic meteorological conditions - as were observed during that period when wet deposition of aerosols is limited. In addition, PM10 are known to have a detrimental impact on health (Pope and Dockery, 2006). There is evidence of past Icelandic eruptions affecting human health in Western Europe, the Laki 1783 eruption being perhaps the most dramatic of such events (Grattan et al., 2003).

The Eyjafjallajökull April 2010 plume constitutes a textbook example of long range transport of trace species in the atmosphere (Stohl, 2001). The fact that the plume affected areas densely covered by a variety of monitoring instruments (Pappalardo and Mattis, 2010; Schumann et al., 2010; Baltensperger et al., 2010) probably makes this event one of the most documented atmospheric long range transport case studies to date. In addition, this plume

\footnotetext{
* Corresponding author. Tel.: +33 344556482 .

E-mail address: augustin.colette@ineris.fr (A. Colette).
}

presented a clear microphysical and chemical signature so that it could be discriminated amongst background trace species in the planetary boundary layer ( $\mathrm{PBL}$ ) whereas this discrimination is notoriously difficult in the context of long range transport of ubiquitous trace species (Colette et al., 2007).

To illustrate the challenges of assessing in near real-time the impact of such an unforeseen event, we choose to rely exclusively on elements that were available in the course of the episode. The structure of the paper reflects the chronology in which these elements became available for decision making. A special focus is given to impacts in France as - unfortunately - most existing operational near real-time air quality monitoring procedures were designed at the national level. The detection of the ash plume by means of ground-based remote sensing constituted the first hint of a possible impact on air quality as the altitude of the plume was decreasing in time above the observatory. The implementation of dedicated forecasts based on an operational chemistry and transport model confirmed the expected intrusion of volcanic ash at the surface. Meanwhile, an emergency air quality monitoring procedure was activated to document the event by means of fast track analysis of filters collected at surface stations. This analysis of in-situ measurements led us to conclude within a few days about the actual impact of the ash plume on air quality. 


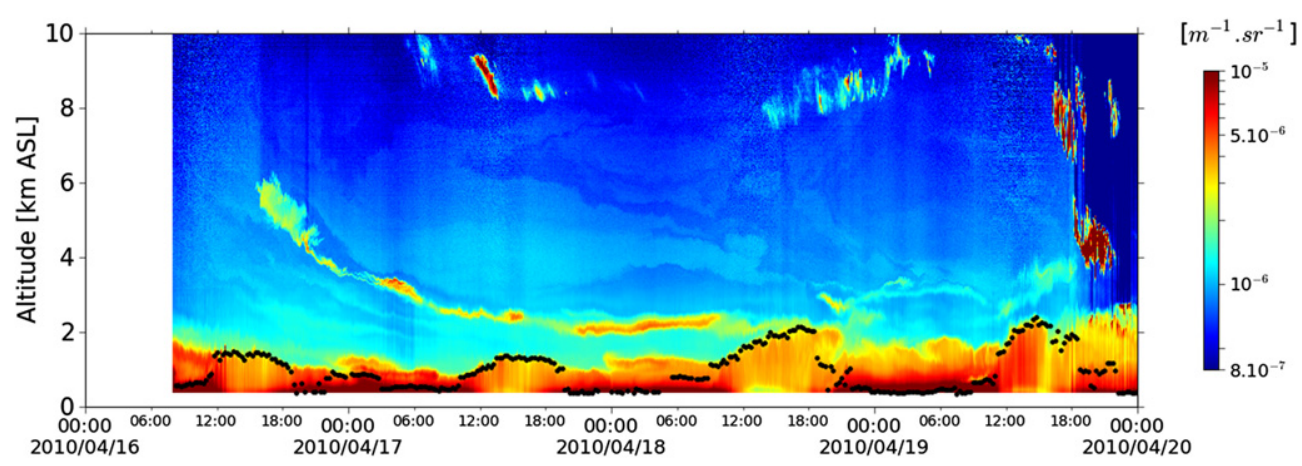

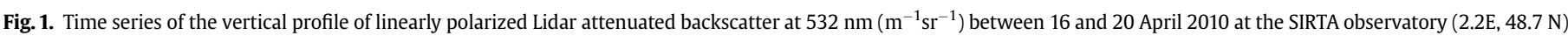

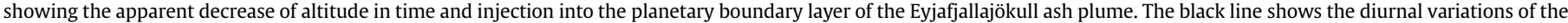
mixing layer depth derived from Lidar observations.

\section{Remote sensing of the ash layer in the free troposphere}

The possible interference of the Eyjafjallajökull plume with the PBL over France was first detected by the atmospheric backscattering Lidars (Light detection and ranging) operated by Institut Pierre-Simon Laplace at the SIRTA observatory $20 \mathrm{~km}$ South of Paris (Haeffelin et al., 2005). Fig. 1 displays the continuous record of the attenuated backscatter at $532 \mathrm{~nm}$ between the 16 and 19 April together with the depth of the PBL inferred with the STRAT algorithm (Morille et al., 2007). Although the remote sensing setup at SIRTA offers a comprehensive documentation of optical properties of the ash layer, we choose to present here exclusively the attenuated backscatter that was the only quantity available in near real-time whereas other physical properties necessitate further post-processing.

The Eyjafjallajökull plume was first observed above the SIRTA observatory at 16UTC on 16 April as a $1000 \mathrm{~m}$ thick layer with a base height at $5000 \mathrm{~m}$ above ground level. The particle depolarization ratio at $532 \mathrm{~nm}$ ranged between $0.3-0.4$ showing that the plume was mainly constituted of non-spherical particles. The 440-870 nm column-integrated Angström exponent measured by a sun-photometer of the Aeronet network decreased significantly from 1.7 to 1.1 at 16UTC, we could thus conclude that the lofted plume contained particles significantly larger than aerosols found in the mixing layer (Dubovik et al., 2002).

In the first $8 \mathrm{~h}$, a relatively fast decrease of the altitude of the volcanic plume was observed. From 17 April 00UTC onwards, the plume sampled above the observatory was much thinner (about $300 \mathrm{~m}$ ) and stabilized at about $2500 \mathrm{~m}$ asl while the depth of the mixing layer did not exceed $1300 \mathrm{~m}$ asl. On 18 April, the enhanced vertical development of the mixing layer, reaching $2000 \mathrm{~m}$ asl, led to the intrusion of volcanic ash into the PBL.

\section{Modeled spatial footprint of the ash layer}

On 15 April, while the London Volcanic Ash Advisory Centre forecasts suggested that the Eyjafjallajökull ash plume might be advected above France, a dedicated air quality forecasting product was designed to assess its possible impact on air quality at the surface using the Chimere regional chemistry and transport model (CTM) (Bessagnet et al., 2009). One of the motivations was to detect if the combined impacts of the volcanic ash plume and anthropogenic particulate pollution sources (industrial activities, transports, and ammonia-rich fertilizer spreading - which is commonplace in spring) would yield detrimental PM10 level.

The Chimere model is a state of the art CTM recognized for its skills at capturing air pollution episodes at the regional scale. It is implemented as part of the official French national air quality forecasting system (www.prevair.org) (Rouïl et al., 2009) and contributes to the Monitoring Atmospheric Composition and Climate (MACC) pre-operational atmospheric service of the GMES Initiative coordinated by the European Centre for Medium-Range Weather Forecasts (ECMWF). In the version used for this study, the model had 30 hybrid sigma-pressure vertical levels extending up to $200 \mathrm{hPa}$ and it was driven by meteorological forcing fields of the ECMWF IFS forecast model at $25 \mathrm{~km}$ horizontal resolution. The results presented here were obtained with ECMWF large scale fields covering the April 14th to April 21st period and released on 21 April, so that these simulations can be considered as a near real time analysis of the event. A passive gaseous tracer was released at the location of the Eyjafjallajökull following the quantitative emission estimates provided by the Hotvolc Service (Labazuy et al., 2010, www.obs.univ-bpclermont. $\mathrm{fr} / \mathrm{SO} /$ televolc/hotvolc/) reflecting the best knowledge we had on 21 April of the volcanic emissions. The fraction of PM finer in size than

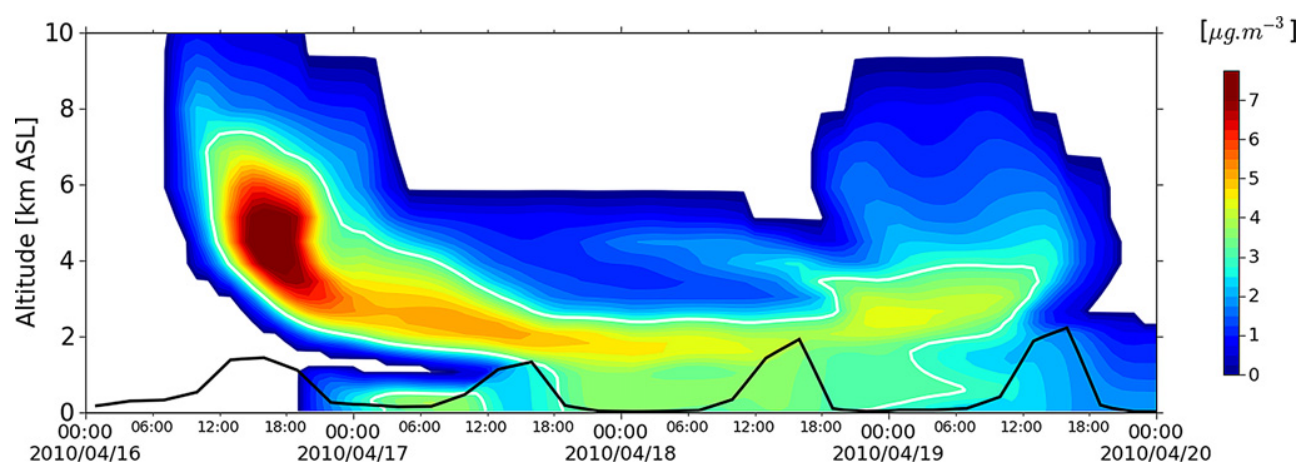

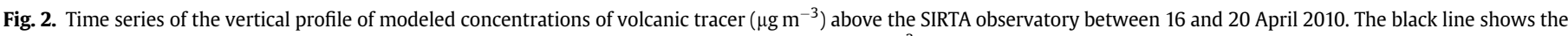
diurnal variations of the modeled planetary boundary layer and the white line highlights the $3 \mu \mathrm{g} \mathrm{m}^{-3}$ isocontour. 


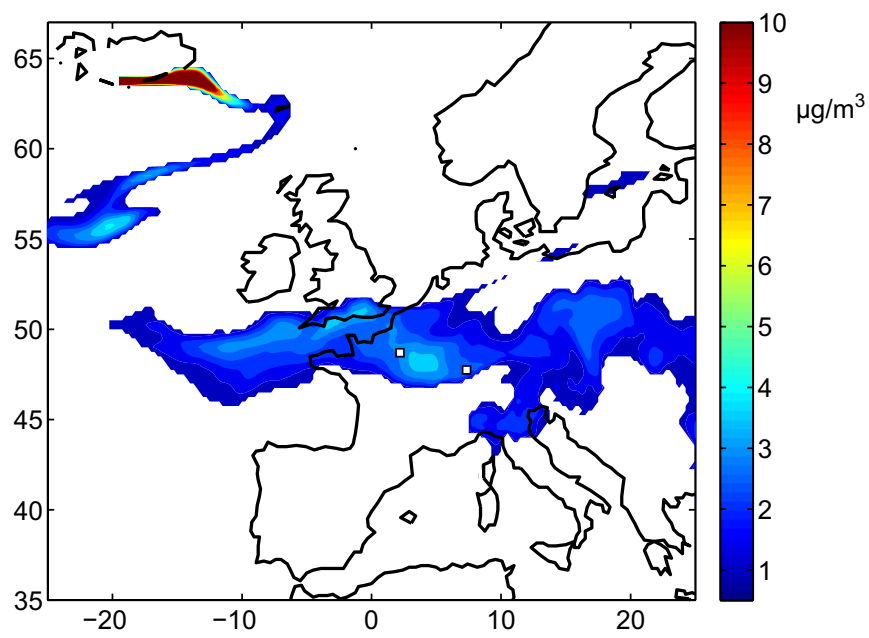

Fig. 3. Geographical footprint of the modeled volcanic plume on 18 April 2010 at 22UTC (vertically averaged below $1000 \mathrm{~m}$ of altitude). The two dots indicate (from West to East) the position of the SIRTA observatory and Mulhouse surface station, respectively.
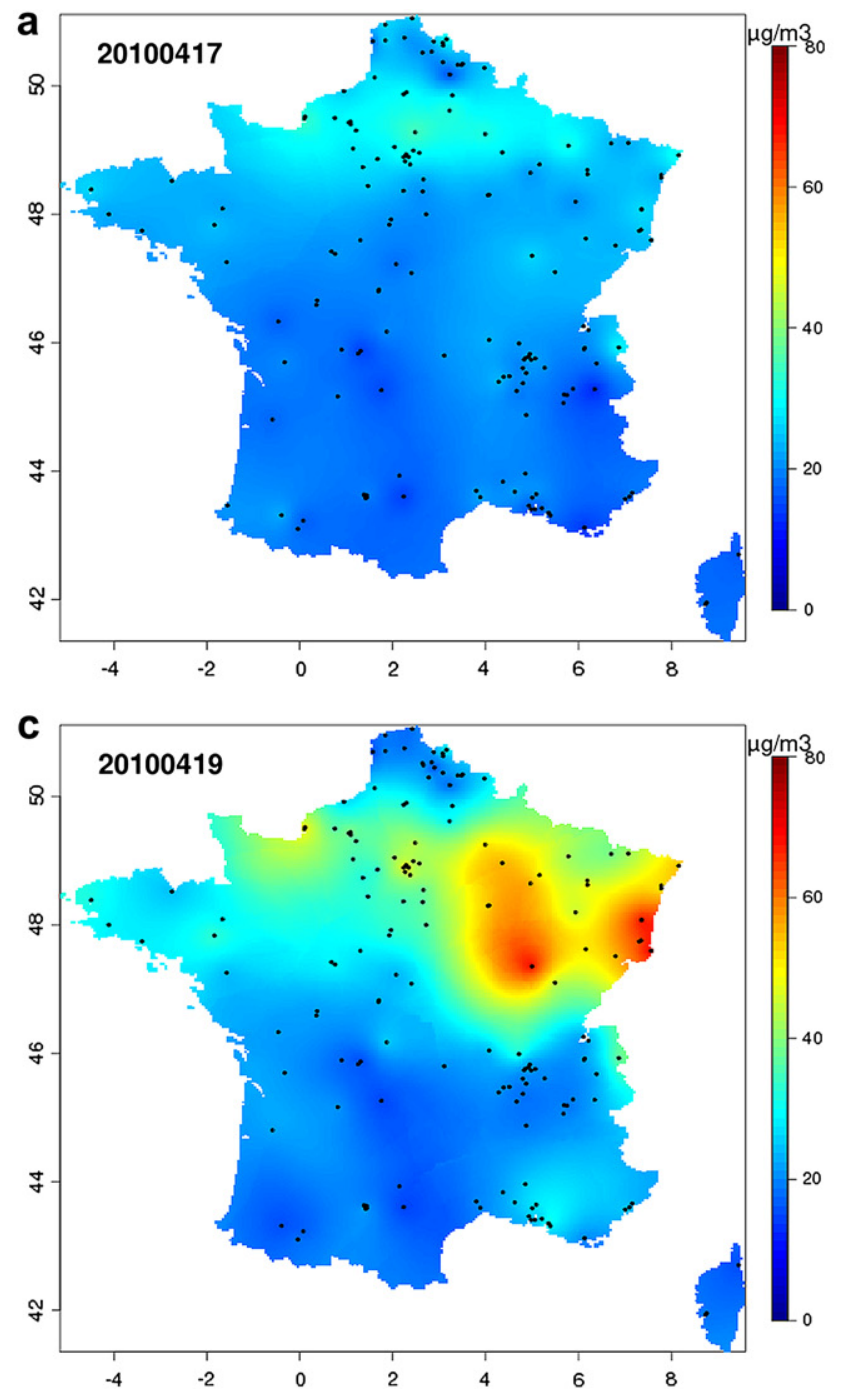

$10 \mu \mathrm{m}$ and thus susceptible to be advected over long distance (20\%) was inferred from a granulometry of ash samples collected at the surface in the vicinity of the volcano (N. Oskarsson, unpublished data, 2010, available from the Nordic Volcanological Center, http:// www2.norvol.hi.is/page/IES-EY-CEMCOM). Nevertheless a gaseous tracer was preferred to particulate matter to avoid further speculation about the particle size distribution in the lofted plume. Total particulate matter was derived (Pavolonis et al., 2006) using Terra-MODIS satellite data and uniformly distributed in the model between the volcano's vent and the maximum altitude of the plume derived from local observations of the Icelandic Meteorological Office and obtained from the Hotvolc service.

Fig. 2 shows the time slice of the modeled concentration of tracers above the SIRTA observatory and can be directly compared to the Lidar data provided in Fig. 1. A number of features of the volcanic plume are well reproduced: its timing of arrival above the observatory, the decrease of its altitude in time and thinning in the first $48 \mathrm{~h}$ and its intrusion towards the surface on 18 April. Other aspects are in disagreement with observations, particularly the modeled increase of surface concentrations starting 17 April and the quantitative concentrations at the surface: about $5 \mu \mathrm{g} \mathrm{m}^{-3}-$ which is much lower than estimates derived from in-situ samples discussed hereafter. Both reflect the very high uncertainties related to the
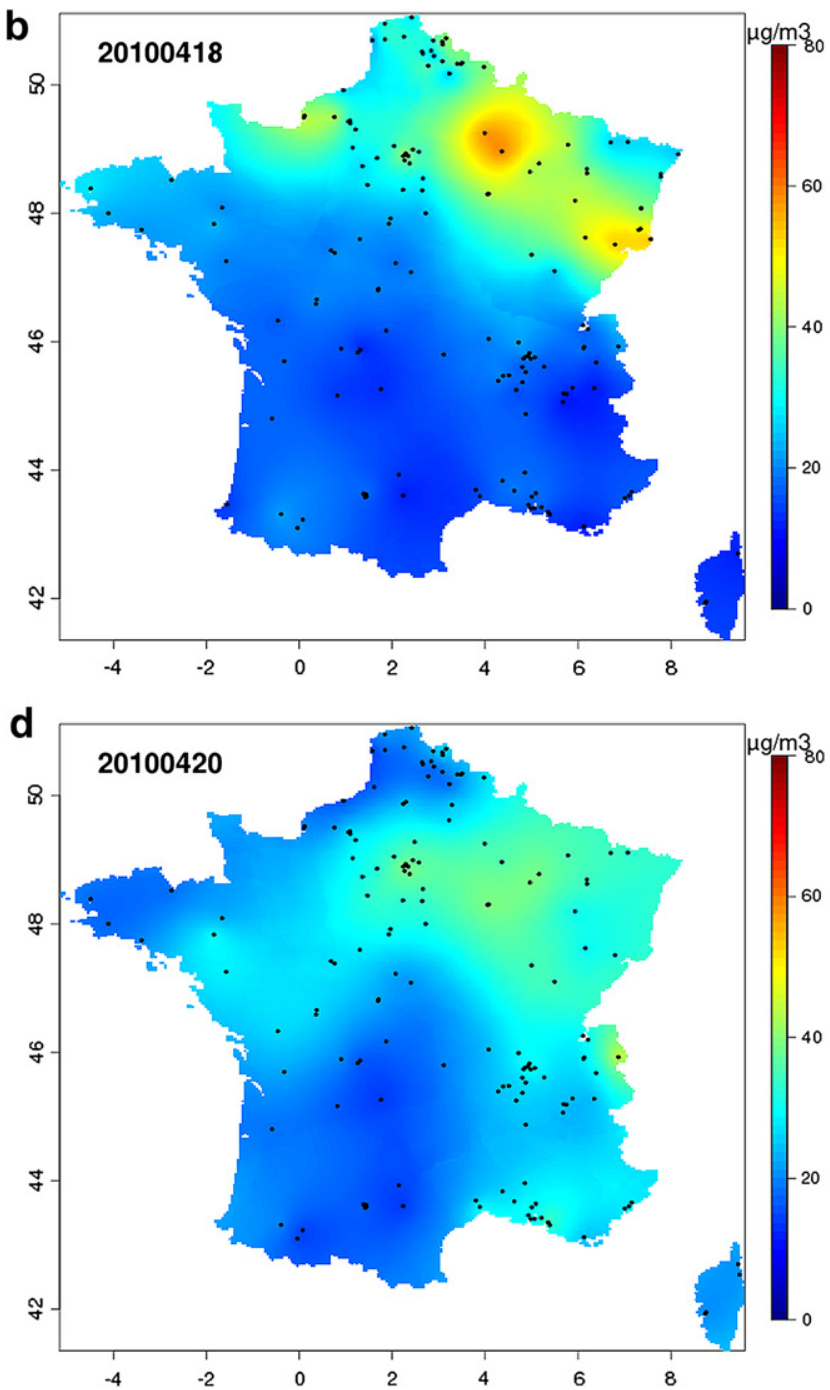

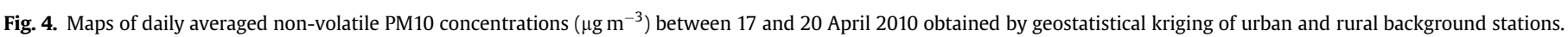


emission source (particle size distribution, injection height, mass flux, temporal variation, etc...). Nevertheless, the qualitative agreement of the timing and morphology of the volcanic plume between model simulations and Lidar observations demonstrates that it is appropriate to make use of the model to extrapolate the horizontal footprint of the event beyond the SIRTA observatory.

Fig. 3 shows the modeled concentration of tracers averaged below $1000 \mathrm{~m}$ of altitude on 18 April 2010 at 18UT. Note that over France, the signal was confined to the North-eastern part of the country, which suggests that the impact of the Eyjafjallajökull plume at the surface would be enhanced in that area. This result is confirmed by real-time measurements of non-volatile PM10 as seen on Fig. 4 that displays daily averages obtained by geostatistical kriging of about 150 surface stations. A clear anomaly is observed in North-Eastern France on April 18th and 19th.

\section{Source apportionment and impact on air quality}

On the basis of real-time Lidar measurements and preliminary model computations following the methodology presented in section 3 (yet using forecast fields instead of the posterior analysis) an emergency air quality monitoring procedure (CARA) was activated on 16 April 2010 in order to investigate the chemical composition of PM10. This procedure has been operated since 2008 by the French central laboratory for air quality monitoring (LCSQA) to monitor and document particulate matter pollution episodes. It builds on an existing monitoring network and includes fast-track chemical analysis at INERIS of PM10 and PM2.5 routinely collected onto $24 \mathrm{~h}$ high volume quartz fiber filters samples at up to thirteen rural and urban background sites in France by local air quality monitoring networks. The chemical characterization included the thermo-optical determination of carbonaceous aerosols (elemental carbon and organic matter) (Cavalli et al., 2010), and the analysis of major soluble species (Nitrate, Sulphate, Ammonium, Calcium and Sodium) using ion chromatography (Mihalopoulos et al., 1997). As volcanic particulate emissions are primarily composed of non carbonaceous and insoluble material, some metals (Aluminium, Iron, and Titanium) were also quantified for the present study by means of inductively coupled plasma optical emission spectrometry after conventional microwave extraction (Mainey and Winberry, 1999). Non-volatile PM2.5/PM10 concentrations are monitored in France by means of Tapered Element Oscillating Microbalance (TEOM), while total PM2.5/PM10 concentrations are monitored using TEOM equipped with Filter Dynamics Measurement systems (FDMS), providing real-time particulate matter information (Favez et al., 2007).

In the week following the Eyjafjallajökull eruption, the CARA emergency procedure was activated at three rural background stations (Jonville, Revin, and Verneuil) and three urban background stations (Rouen, Lens, and Mulhouse) all of them located in Northern France. Amongst these stations, the PM10 record obtained at the Mulhouse station (geographical position represented on Fig. 3) exhibited the most outstanding signature of volcanic tracers during that period. Similar features, yet more moderate in magnitude, were observed at the five other sampling stations.

As presented in Fig. 5a, a significant increase of PM10 levels was observed at the Mulhouse station during the afternoon of 18 April with an important contribution of coarse and non volatile particles that remained at relatively high levels for about two days. More specifically, non-volatile PM10 reached $56 \mathrm{\mu g} \mathrm{m}^{-3}$ on average on 18 and 19 April against $22 \mathrm{mg} \mathrm{m}^{-3}$ on average for the two previous days - a $34 \mu \mathrm{g} \mathrm{m}^{-3}$ excess of non-volatile PM10. This feature rules out a possible significant impact of semi-volatile secondary aerosols such as ammonium nitrate as was initially forecasted - independently of the occurrence of the Eyjafjallajökull eruption - by the Prev'air System for 19 April as a result of the combination of nitric acid formation and agricultural fertilizer spreading (and subsequent ammonia emissions).

Chemical analyses performed on daily filter samples confirmed the crustal origin of the particles responsible for this PM10 anomaly. On average over 18 and 19 April, the amount of non-carbonaceous and insoluble materials reached up to $42 \mu \mathrm{g} \mathrm{m}^{-3}$, representing $65 \%$ of total PM10 whereas on 16 and 17 April they constituted less than 35\% of total PM10: a more usual figure at urban background sites (Putaud et al., 2004). The overall excess of non-carbonaceous and insoluble PM10 observed on 18 and 19 April was thus $28 \mu \mathrm{g} \mathrm{m}^{-3}$ in good agreement with the non-volatile PM10 excess mentioned above. The plume dispersion footprint presented in Section 3 and validated against the remote sensing data discussed in Section 2 rules out a possible significant contribution of Saharan dust to these high concentrations of crustal particles. It was also confirmed by means of Lagrangian trajectory and plume dispersion modelling (not shown).

A last quantitative estimate of the impact of the Eyjafjallajökull plume at the surface was provided by the analysis of Aluminium (Al), Iron (Fe) and Titanium (Ti) on sampled filters. Their synchronous increase and subsequent decrease during that episode in Mulhouse (Fig. 5b) is quite unusual in ambient air (Gotschi et al., 2005). Compared to levels observed on 16 and 17 April, the respective anomaly of $\mathrm{Al}, \mathrm{Fe}$, and Ti reached $1.7,2.1$, and $0.35 \mu \mathrm{g} \mathrm{m}^{-3}$ on average on 18 and 19 April. Estimates of the chemical composition of the Eyjafjallajökull plume provided by the Icelandic Institute of Earth Sciences (N. Óskarsson, unpublished data, 2010, available from the Nordic Volcanological Center, http://www2.norvol.hi.is/page/IESEY-CEMCOM) indicate that $\mathrm{Al}, \mathrm{Fe}$, and $\mathrm{Ti}$ constituted about $8.3 \%$, $7.5 \%$ and $1.0 \%$ of the ash and scoria collected in the vicinity of the volcano. These estimates constituted the best knowledge available at that time of the chemical composition of the Eyjafjallajökull plume. Assuming that these ratios can be applied to our samples, we could derive a rough estimate of the ash concentration in Mulhouse: from 20 to $38 \mu \mathrm{g} \mathrm{m}^{-3}$ on average over 18 and 19 April.
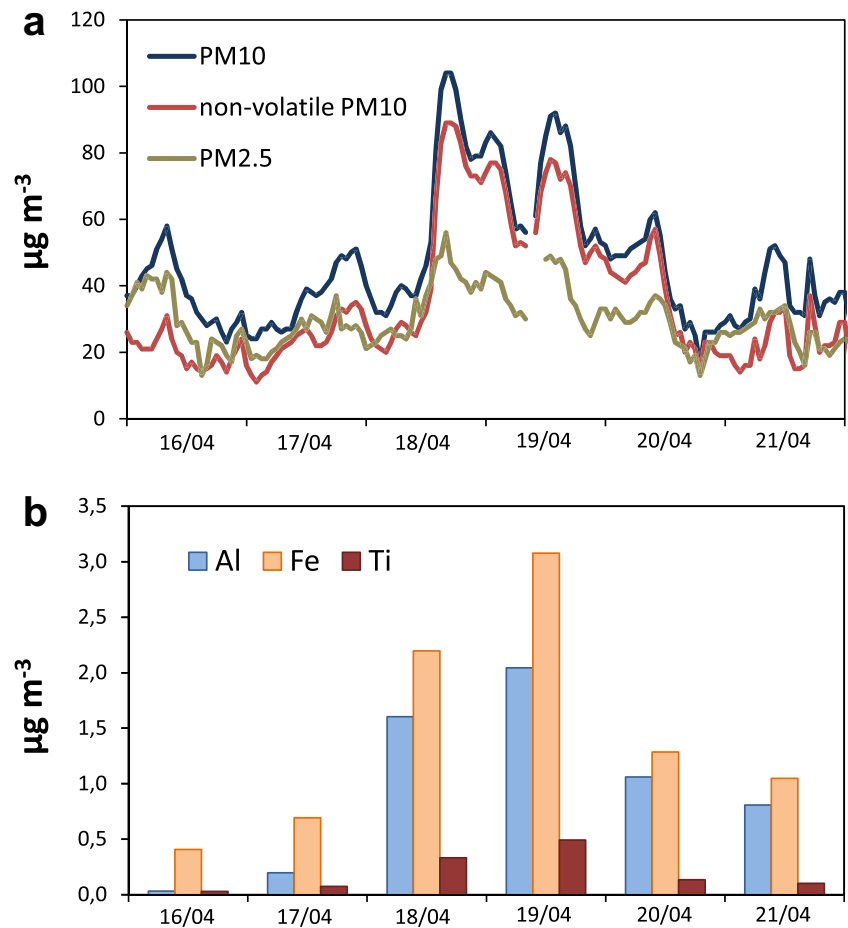

Fig. 5. (a) Hourly time series of total PM10, non-volatile PM10 and total PM2.5 concentrations $\left(\mu \mathrm{g} \mathrm{m}^{-3}\right)$ measured at the Mulhouse station between 16 and 21 April 2010. (b) Daily concentrations ( $\mu \mathrm{g} \mathrm{m}^{-3}$ ) of aluminium ( $\mathrm{Al}$ ), iron (Fe) and titanium (Ti) in PM10 at the Mulhouse station between 16 and 21 April 2010. 


\section{Conclusion}

All these estimations carry significant uncertainties, including aerosol sampling artefacts, instrumental and analytical errors, chemical composition of the emissions, and chemical transformation in the ash plume during its transport. Nevertheless, our assessment is strengthened by the diversification of the proxies since we relied on 5 independently measured quantities ( $\mathrm{Al}, \mathrm{Fe}, \mathrm{Ti}$, non volatile PM10, non-carbonaceous and insoluble PM10). Altogether, these estimates point towards a concentration of volcanic ash in the PBL of about $30 \pm 10 \mu \mathrm{g} \mathrm{m}^{-3}$ on average over 18 and 19 April in Mulhouse. This estimate constitutes probably an upper bound of the impact of the April 2010 Eyjafjallajökull eruption on air quality in France as the signal in Mulhouse was the most significant in the whole dataset available for this study (six in-situ sampling stations and $150+$ automated non-volatile PM10 recorders). While we conclude that the April 2010 Eyjafjallajökull ash plume did have an impact at the surface, we also find that it cannot be considered as a major event of long range transport impacting surface air quality.

Beyond these conclusions, the present paper also illustrates the relevance of multidisciplinary approaches in operational environmental forecasting and monitoring. Building on the lessons learnt from the Eyjafjallajökull April 2010 eruption the authors advocate to foster the development of such approaches using existing frameworks such as the European Global Monitoring for Environment and Security (GMES) initiative.

\section{Acknowledgements}

We wish to acknowledge the dedication of the SIRTA technical team providing uninterrupted measurements during the April 2010 episode as well as all the local French air quality monitoring agencies participating in the CARA network for surface measurements. Observatoire de Physique du Globe de Clermont-Ferrand provided the estimate of the volcanic emissions through the Hotvolc Service. Aerosol optical depth data was obtained from the AERONET network.

\section{References}

Baltensperger, U., Bukowiecki, N., Zieger, P., Juranyi, Z., Gysel, M., Weingartner, E., Neininger, B., Hueglin, C., Ulrich, A., Wichser, A., Kaegi, R., 2010. In situ measurements of physical and chemical properties of the volcanic ash aerosol from the Eyjafjallajökull eruption. Geophysical Research Abstracts 12, 15711

Bessagnet, B., Menut, L., Curci, G., Hodzic, A., Guillaume, B., Liousse, C., Moukhtar, S., Pun, B., Seigneur, C., Schulz, M., 2009. Regional modeling of carbonaceous aerosols over Europe - focus on secondary organic aerosols. Journal of Atmospheric Chemistry 61, 175-202.

Cavalli, F., Viana, M., Yttri, K.E., Genberg, J., Putaud, J.-P., 2010. Toward a standardised thermal-optical protocol for measuring atmospheric organic and elemental carbon: the EUSAAR protocol. Atmospheric Measurement Techniques 3, 79-89.

Colette, A., Menut, L., Haeffelin, M., Morille, Y., 2007. Impact of the transport of aerosols from the free troposphere towards the boundary layer on the air quality in the Paris area. Atmospheric Environment 42, 390-402.
Dubovik, O., Holben, B., Eck, T.F., Smirnov, A., Kaufman, Y.J., King, M.D., Tanré, D., Slutsker, I., 2002. Variability of absorption and optical properties of key aerosol types observed in worldwide locations. Journal of the Atmospheric Sciences 59, 590-608.

Favez, O., Cachier, H., Sciare, J., Le Moullec, Y., 2007. Characterization and contribution to PM2.5 of semi-volatile aerosols in Paris, France. Atmospheric Environment 41, 7969-7976.

Gotschi, T., Hazenkamp-von Arx, M.E., Heinrich, J., Bono, R., Burney, P., Forsberg, B., Jarvis, D., Maldonado, J., Norback, D., Stern, W.B., Sunyer, J., Toren, K., Verlato, G., Villani, S., Kunzli, N., 2005. Elemental composition and reflectance of ambient fine particles at 21 European locations. Atmospheric Environment 39, 5947-5958.

Grattan, J., Durand, M., Taylor, S., 2003. Atmospheric, climatic and environmental impacts of volcanic emissions. In: Oppenheimer, C., Pyle, D.M., Barclay, J. (Eds.), Volcanic Degassing, vol. 213. Geological Society of London, pp. 401-414.

Haeffelin, M., Barthès, L., Bock, O., Boitel, C., Bony, S., Bouniol, D., Chepfer, $\mathrm{H}$. Chiriaco, M., Cuesta, J., Delanoë, J., Drobinski, P., Dufresne, J.-L., Flamant, C. Grall, M., Hodzic, A., Hourdin, F., Lapouge, F., Lemaître, Y., Mathieu, A., Morille, Y., Naud, C., Noël, V., O’Hirok, W., Pelon, J., Pietras, C., Protat, A., Romand, B., Scialom, G., Vautard, R., 2005. SIRTA, a ground-based atmospheric observatory for cloud and aerosol research. Annales Geophysicae 23, 253-275.

Labazuy, P., Gouhier, M., Hervo, M., Freville, P., Quehennen, B., Donnadieu, F., Guehenneux, Y., Cacault, P., Colomb, A., Gayet, J.-F., Pichon, J.-M., Rivet, S. Schwarzenböck, A., Sellegri, K., 2010. Monitoring the Eyjafjöllvolcanic plume using OPGC platforms: remote sensing and in-situ measurements. Geophysical Research Abstracts 12, 15763.

Mainey, A., Winberry, W.T., 1999. Chemical species analysis of filter-collected suspended particulate matter, Method IO-3.1: selection, preparation, and extraction of filter material. In: Manning, J.A., Burckle, J.O., Hedges, S., McElroy, F.F. (Eds.), Compendium of Methods for the Determination of Inorganic Compounds in Ambient Air. US-EPA, Cincinnati.

Mihalopoulos, N., Stephanou, E., Kanakidou, M., Pilitsidis, S., Bousquet, P., 1997. Tropospheric aerosol ionic composition above the Eastern Mediterranean Area. Tellus B 49, 314-326.

Morille, Y., Haeffelin, M., Drobinski, P., Pelon, J., 2007. STRAT: An automated algorithm to retrieve the vertical structure of the atmosphere from single-channel lidar data. Journal of Atmospheric and Oceanic Technology 24, 761-775.

Pappalardo, G., Mattis, I., 2010. Dispersion and evolution of the Eyjafjallajökull ash plume over Europe: vertically resolved measurements with the European LIDAR network EARLINET. Geophysical Research Abstracts 12, 15731.

Pavolonis, M.J., Feltz, W.F., Heidinger, A.K., Gallina, G.M., 2006. A daytime complement to the reverse absorption technique for improved automated detection of volcanic ash. Journal of Atmospheric and Oceanic Technology 23, 1422-1444.

Pope III, C.A., Dockery, D.W., 2006. Health effects of fine particulate air pollution: lines that connect. Journal of Air Waste Management 56, 709-742.

Putaud, J.-P., Raes, F., Van Dingenen, R., Bruggemann, E., Facchini, M.-C., Decesari, S., Fuzzi, S., Gehrig, R., Huglin, C., Laj, P., Lorbeer, G., Maenhaut, W., Mihalopoulos, N. Muller, K., Querol, X., Rodriguez, S., Schneider, J., Spindler, G., ten Brink, H., Torseth, K., Wiedensohler, A., 2004. A European aerosol phenomenology-2: chemical characteristics of particulate matter at kerbside, urban, rural and background sites in Europe. Atmospheric Environment 38, 2579-2595.

Rouïl, L., Honoré, C., Bessagnet, B., Malherbe, L., Meleux, F., Vautard, R., Beekmann, M., Flaud, J.-M., Dufour, A., Martin, D., Peuch, A., Peuch, V.-H., Elichegaray, C., Poisson, N., Menut, L., 2009. PREV'AIR: an operational forecasting and mapping system for air quality in Europe. Bulletin of the American Meteorological Society $90,73-83$.

Schumann, U., Weinzierl, B., Reitebuch, O., Minikin, A., Schlager, H., Rahm, S., Scheibe, M., Lichtenstern, M., Forster, C., 2010. Volcanic ash cloud observations with the DLR-Falcon over mid-europe during and after airspace. Geophysical Research Abstracts 12, 15736.

Stohl, A., 2001. A 1-year Lagrangian "climatology" of airstreams in the Northern Hemisphere troposphere and lowermost stratosphere. Journal of Geophysical Research 106, 7263-7279.

Thordarson, T., 2010. The 2010 Eyjafoll eruptions, south Iceland: on-site observations and first analytical results. Geophysical Research Abstracts 12, 15729. 